\author{
Y.Q. ZHANG ${ }^{1,2}$ \\ J.X. WANG ${ }^{1}$ \\ X. CHEN $^{1}$ \\ J. LIANG ${ }^{1}$ \\ L. JIANG ${ }^{1}$ \\ Y.L. SONG ${ }^{1, \infty}$ \\ D.B. $\mathrm{ZHU}^{1}$
}

\title{
Enhancing fluorescence of tricolor fluorescent powders by silica inverse opals
}

${ }^{1}$ Key Laboratory of Organic Solids, Institute of Chemistry, Chinese Academy of Sciences, Beijing 100080, P.R. China

${ }^{2}$ College of Chemistry and Chemical Engineering, Yan'an University, Yan'an, Shan'xi 716000, P.R. China

\section{(C) Springer-Verlag 2007}

Owing to an unfortunate error on the part of Springer, Fig. 1b and Fig. 1c were transposed. The correct figure is shown here.
Appl. Phys. A 87, 271 (2007)

DOI 10.1007/s00339-006-3830-7

Published online: 2 February 2007

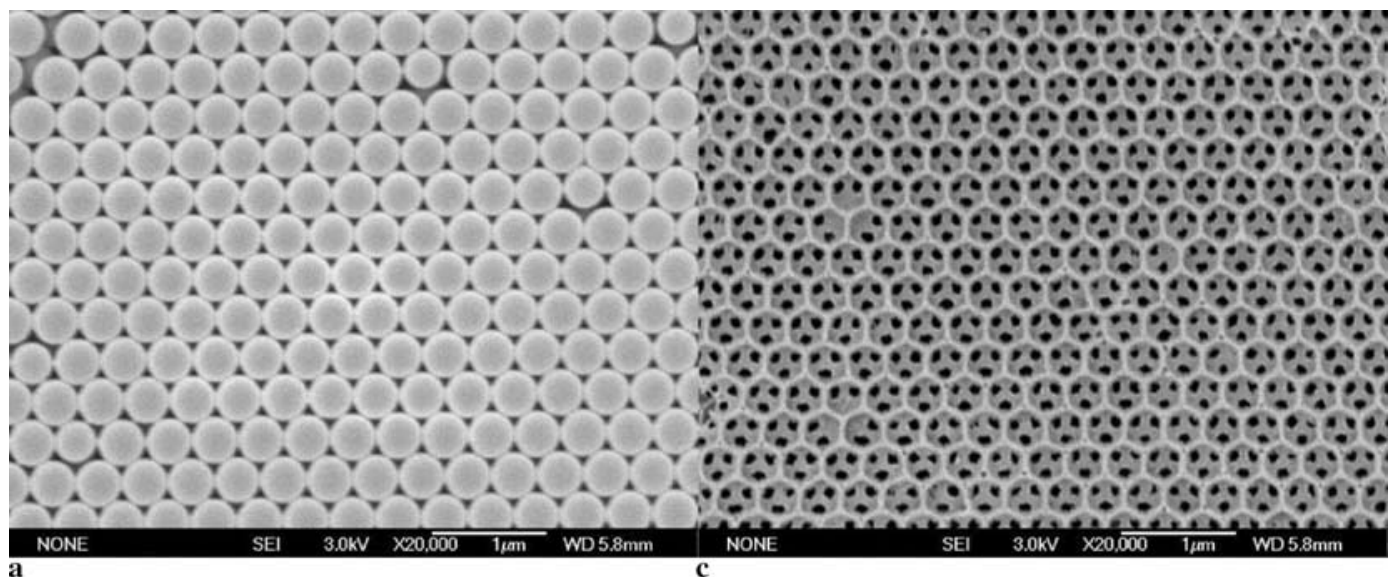

a

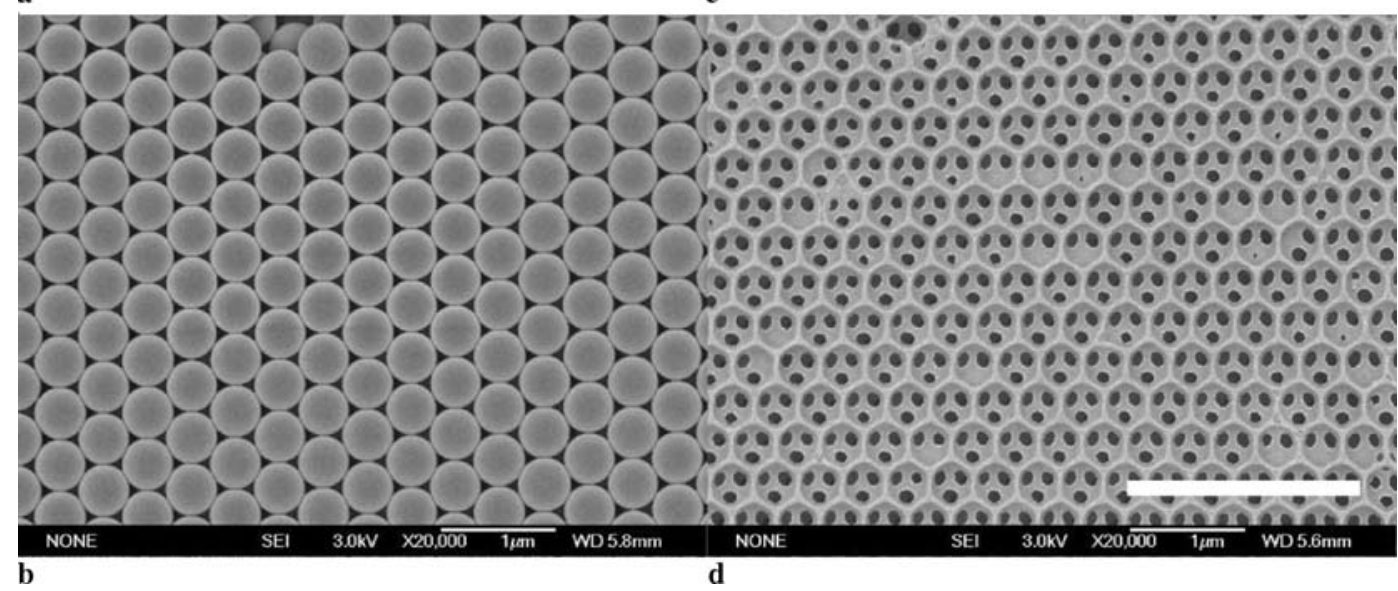

FIGURE 1 The SEM images of P(St-MMA-AA) opal templates with diameters of $410 \mathrm{~nm}$ (a) and $440 \mathrm{~nm}$ (b) and of corresponding $\mathrm{SiO}_{2}$ inverse opals with macropore diameters of $\sim 320 \mathrm{~nm}$ (c) and $370 \mathrm{~nm}$ (d), respectively. The scale bar is $2 \mu \mathrm{m}$

Fax: +86-10-8267-2719, E-mail: ylsong@iccas.ac.cn The online version of the original article can be found at http://dx.doi.org/10.1007/s00339-006-3830-7 